\title{
Recessive aplasia cutis congenita of limbs
}

INSERM

\section{Source}

INSERM. (1999). Orphanet: an online rare disease and orphan drug data base. Recessive aplasia cutis congenita of limbs. ORPHA:1115

Recessive aplasia cutis congenita of limbs is an extremely rare variant of aplasia cutis congenita (ACC; see this term) characterized by the cong enital absence of skin on the upper and/or lower limbs, with these lesions usually healing spontaneously resulting in a hypotrichotic scar. Recessive ACC of limbs may be associated with junctional epidermolysis bullosa (see this term). The inheritance was hypothesized to be autosomal recessive. There have been no further descriptions in the literature since 1980. 